Health Policy Research

\title{
E Assessment of the Trends in Medical Use and Misuse of Opioid Analgesics from 2004 to 2011
}

\author{
Sairam Atluri, MD', Gururau Sudarshan, MD², and Laxmaiah Manchikanti, MD³
}

\footnotetext{
From: ${ }^{\text {TTri-State Spine Care }}$ Institute, Cincinnati, $\mathrm{OH}$; ${ }^{2}$ Cincinnati Pain Management Consultants, Cincinnati, $\mathrm{OH}$; 3Pain Management Center of Paducah, Paducah, KY, and University of Louisville, Louisville, KY

Dr. Atluri is Medical Director, Tri-State Spine Care Institute, Cincinnati, $\mathrm{OH}$.

Dr. Sudarshan is Medical Director, Cincinnati Pain Management Consultants, Cincinnati, $\mathrm{OH}$.

Dr. Manchikanti is Medical Director of the Pain

Management Center of Paducah, Paducah, KY, and Clinical Professor Anesthesiology and Perioperative Medicine, University of Louisville, Louisville, KY.

Address Correspondence: Sairam Atluri MD Tri State Spine Care Institute 7655 Five Mile Road, Suite 117 Cincinnati, $\mathrm{OH} 45230$

E-mail:saiatluri@gmail.com

Disclaimer: There was no external funding in the preparation of this manuscript. Conflict of interest: Each author

certifies that he or she, or a member of his or her immediate

family, has no commercia association (i.e., consultancies, stock ownership, equity interest, patent/licensing arrangements, etc.) that might pose a conflict of interest in connection with the submitted manuscript.

Manuscript received o1-23-2014 Accepted for publication: 01-30-2014

Free full manuscript: www.painphysicianjournal.com
}

Background: The epidemic of medical use and abuse of opioid analgesics is linked to the economic burden of opioid-related abuse and fatalities in the United States. Multiple studies have estimated the extent to which prescription opioid analgesics contribute to the national drug abuse problem; studies also assessing the trends in medical use and abuse of opioid analgesics have confirmed the relationship between increasing medical use of opioids and increasing fatalities.

The available data is limited until 2002..

Study Design: Retrospective analysis of data from 2004 to 2011 from 2 databases: Automation of Reports and Consolidated Orders System (ARCOS) for opioid use data and Drug Abuse Warning Network (DAWN) for drug misuse data.

Objective: To determine the proportion of drug abuse related to opioid analgesics and the various trends in the medical use and abuse of 8 opioid analgesics commonly used to treat pain: buprenorphine, codeine, fentanyl, hydrocodone, hydromorphone, methadone, morphine, and oxycodone.

Methods: The data obtained from DAWN is a nationally representative sample of hospital emergency department admissions resulting from drug abuse.

Main outcome measure was the identification of trends in the medical use and misuse of opioid analgesics from 2004 to 2011

Results: From 2004 to 2011, there was an increase in the medical use of all opioids except for a $20 \%$ decrease in codeine. The abuse of all opioids including codeine increased during this period. Increases in medical use ranged from 2,318\% for buprenorphine to 35\% for fentanyl, including $140 \%$ for hydromorphone, $117 \%$ for oxycodone, $73 \%$ for hydrocodone, $64 \%$ for morphine, and $37 \%$ for methadone. The misuse increased 384\% for buprenorphine with available data from 2006 to 2011 , whereas from 2004 to 2011, it increased $438 \%$ for hydromorphone, $263 \%$ for oxycodone, $146 \%$ for morphine, $107 \%$ for hydrocodone, $104 \%$ for fentanyl, $82 \%$ for methadone, and 39\% for codeine.

Comparison of opioid use showed an overall increase of 1,448\% from 1996 to 2011, with increases if 690\% from 1996 to 2004 and 100\% from 2004 to 2011. In contrast, misuse increased more dramatically: $4,680 \%$ from 1996 to 2011, with increases of 1,372\% from 1996 through 2004 and $245 \%$ from 2004 to 2011 . The number of patients seeking rehabilitation for substance abuse also increased $187 \%$ for opioids, whereas it increased $87 \%$ for heroin, $40 \%$ for marijuana, and decreased $7 \%$ for cocaine.

Limitations: Limitations of this assessment include the lack of data from 2003, lack of data available on meperidine, and that the aggregate data systems used in the study did not identify specific formulations or commercial products.

Conclusion: The present trend of continued increase in the medical use of opioid analgesics appears to contribute to increases in misuse, resulting in multiple health consequences.

Key words: Medical use of opioids, inappropriate use of opioids, abuse of opioids, opioid-related fatalities, Automation of Reports and Consolidated Orders System (ARCOS), Drug Abuse Warning Network (DAWN), International Narcotics Control Board (INCB)

Pain Physician 2014; 17:E119-E128 
1 he growing epidemic of the medical use and abuse of opioid analgesics is closely linked to the economic burden of opioid-related abuse and fatalities in the United States, and continues despite the alleged undertreatment of pain, with the introduction of long-acting opioids, a growing awareness of the right to pain relief, JCAHO standards, and liberalization of laws governing opioid prescribing by the state medical boards (1-24). However, this explosive increase of opioid use, associated closely with abuse and related fatalities as it is known now, has been largely based on poor science and misinformation in relation to safety and effectiveness even when prescribed by a physician and taken appropriately $(14,15,19-26)$. The International Narcotics Control Board (INCB), in 2011, reported that the abuse of prescription drugs was growing rapidly around the world with more people abusing legal narcotics than heroin, cocaine, and ecstasy combined (27). Opioid sales in the United States increased 7-fold from 1997 to 2010, from a morphine equivalence of $96 \mathrm{mg}$ per person to $710 \mathrm{mg}$ per person (28), with opioid related deaths reaching 16,651 in 2010 from 4,030 in 1999, an increase of 313\% $(14,16)$. Consequently, unintentional drug poisoning from opioid analgesics caused more overdose deaths in 2007 than heroin and cocaine combined. In addition, for every unintentional opioid analgesic overdose death, 9 patients were admitted for substance abuse treatment, 35 visited emergency departments, 161 reported drug abuse or dependence, and 461 reported nonmedical use of opioid analgesics $(14,16,23)$. A Government Accountability Office (GAO) report also concluded that key measures of prescription pain reliever abuse and misuse increased from 2003 to 2009 (17). Inocencio et al (6) showed that opioid related poisoning causes a substantial burden to the United States each year with total estimated costs of approximately $\$ 20.4$ billion.

Multiple studies have estimated the extent to which prescription opioid analgesics contribute to the national drug abuse problem (1-9). Joranson et al (1) assessed the trends in medical use and abuse of opioid analgesics from 1990 to 1996 and concluded that the trend of increasing medical use of opioid analgesics to treat pain did not appear to contribute to increases in health consequences of opioid analgesic abuse, despite documented increases in the medical use of morphine of $59 \%$, fentanyl of $1,168 \%$, oxycodone of $23 \%$, and hydrocodone of $19 \%$. Gilson et al (2), in reassessing trends in the medical use and abuse of opioid analgesics and implications for diversion control from 1997 to 2002, opined that an increase in the medical use of opioids is a general indicator of progress in providing pain relief, ignoring the growing public health problem of abuse of opioids. In contrast, in 2009 the prevalence of opioid poisoning visits to the emergency department was estimated to be 534,490 or 174 per 100,000 population, a significant increase from 119,184 in 2002 (6). These increases are despite a wide body of literature corroborating the fact that the explosive increase in therapeutic opioids contributes to increasing fatalities $(1-9,14-17,23-25,27,28)$.

Due to the lack of available data on the trends of opioid use and abuse since 2002, this descriptive study was undertaken to assess the medical use and abuse of opioid analgesics from 2004 to 2011.

\section{Methods}

In this assessment, 8 opioids (buprenorphine, codeine, fentanyl, hydrocodone, hydromorphone, methadone, morphine, and oxycodone) were assessed for medical use and abuse. These drugs were chosen because of their common utility and availability of data from The Drug Abuse Warning Network (DAWN) (29) and Automation of Reports and Consolidated Orders System (ARCOS) (30).

\section{Data on Medical Use of Opioids}

ARCOS, a federal, computerized data system, required by the 1970 Controlled Substances Act, monitors the lawful distribution of controlled substances in Schedules I and II and narcotic substances in Schedule III from manufacturers to the retail level of consumption, including hospitals, pharmacies, and licensed practitioners (30). The Drug Enforcement Administration (DEA) makes reports on ARCOS data, providing information on individual states and national totals. Information is provided for each drug in total grams and grams per 100,000 population. ARCOS classifies the drug use according to the categories of drugs dispensed by pharmacies, hospitals, practitioners, teaching institutions, and narcotic treatment programs.

\section{Data on Drug Abuse Trends}

DAWN provides estimates of the health consequences of the nonmedical use of the individual drugs by a large scale, ongoing retrospective survey of medical records (29). The system collects information from DAWN-affiliated hospital emergency departments, not only to identify substances that are abused, but also to monitor drug abuse patterns and trends in detecting 
new drug entities and combinations. Drug abuse in the DAWN system is defined as the nonmedical use of a substance for psychic effect, dependence, or suicide attempt or gesture. Consequently, drug abuse can involve the use of illicit drugs or any other substances, prescription drugs in a manner inconsistent with an accepted medical practice, and over-the-counter drugs contrary to approved labeling (29).

\section{Data on Rehabilitation}

The category of visits referred for rehabilitation described as "seeking detox" includes various situations for admission for detoxification. However, detox may also be sought through other avenues (e.g., direct admission to a hospital, services provided through private clinics, entry into programs outside the community) (29).

\section{Exclusions}

Since the methodology of collecting data was redesigned after year 2004, DAWN does not recommend comparing data between years before and after 2003. Consequently, in this assessment we compared DAWN data to ARCOS from 2004 onwards (31). The data from narcotic treatment programs was also not available. Meperidine was excluded in this analysis as there was no data available from DAWN since 2004, compared to previous evaluations $(1,2)$.

\section{Results}

From 2004 to 2011,7 of the 8 opioids in the study had an increased use except codeine (Table 1). The maximal increase was for buprenorphine (2,318\%), followed by hydromorphone $(140 \%)$ and oxycodone (117\%). Hydrocodone, morphine, methadone, and fentanyl have increased use of $73 \%, 64 \%, 37 \%$, and $35 \%$, respectively. Codeine use decreased by $20 \%$.

Figure 1 illustrates the correlation in the use and misuse of opioids between 2004 and 2011 based on medical use data derived from ARCOS and misuse data derived from DAWN.

From 2004 to 2011, DAWN encounters increased for all 8 opioids included in the study (Table 2). DAWN information was not available for buprenorphine during 2004 and 2005. Hydromorphone had the highest increase in DAWN mentions of $438 \%$, followed by buprenorphine (384\%) and oxycodone (263\%). Fentanyl, hydrocodone, methadone, morphine, and codeine had increased mentions by $104 \%, 107 \%, 82 \%, 146 \%$, and $39 \%$, respectively (Table 2). Despite lower use, codeine had increased misuse. Medical use and misuse of all opioids in the study increased by $65 \%$ and $165 \%$, respectively (Table 2 ).

Comparison of DAWN and ARCOS data as in the previous studies $(1,2)$, with the inclusion of 5 opioids from 1996 to 2011, showed a dramatic increase in the use $(1,448 \%)$ and misuse $(4,680 \%)$ of prescription opioids. Most of this increase was from 1996 to 2004

Table 1. Medical use of opioids based on Automation of Reports and Consolidated Orders System (ARCOS).

\begin{tabular}{|c|c|c|c|c|c|c|c|c|c|}
\hline \multirow[b]{2}{*}{ Drug Name } & \multicolumn{8}{|c|}{ Grams per Year: } & \multirow{2}{*}{ 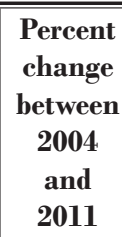 } \\
\hline & 2004 & 2005 & 2006 & 2007 & 2008 & 2009 & 2010 & 2011 & \\
\hline Buprenorphine & 70,332 & 157,292 & 287,099 & 504,646 & 879,119 & $1,220,411$ & $1,485,625$ & $1,700,414$ & $2,318 \%$ \\
\hline Codeine & $211,20,703$ & $19,233,231$ & $18,762,910$ & $18,840,315$ & $18,101,844$ & $17,012,401$ & $16,141,772$ & $16,815,663$ & $(-20 \%)$ \\
\hline Fentanyl & 371,886 & 391,806 & 428,665 & 463,338 & 480,564 & 473,073 & 529,000 & 501,831 & $35 \%$ \\
\hline Hydrocodone & $24,472,516$ & $26,360,982$ & $29,856,315$ & $35,867,499$ & $35,551,034$ & $37,754,130$ & $39,096,893$ & $42,395,540$ & $73 \%$ \\
\hline Hydromorphone & 657,419 & 787,606 & 901,660 & $1,031,515$ & $1,175,595$ & $1,339,610$ & $1,407,921$ & $1,580,650$ & $140 \%$ \\
\hline Methadone & $4,747,852$ & $5,428,222$ & $6,621,685$ & 722,8217 & $6,654,715$ & $6,779,267$ & $6,719,980$ & $6,483,066$ & $37 \%$ \\
\hline Morphine & $14,387,855$ & $15,340,541$ & $17,507,146$ & $19,051,319$ & $20,609,643$ & $22,271,468$ & $22,915,626$ & $23,645,892$ & $64 \%$ \\
\hline Oxycodone & $29,339,217$ & $30,866,100$ & $37,034,213$ & $45,467,583$ & $48,973,049$ & $55,759,038$ & $63,691,983$ & $63,565,457$ & $117 \%$ \\
\hline $\begin{array}{l}\text { Total of Study } \\
\text { Opioids }\end{array}$ & $95,167,780$ & $98,565,780$ & $111,399,693$ & $128,454,432$ & $132,425,563$ & $142,609,398$ & $151,988,800$ & $156,688,513$ & $65 \%$ \\
\hline
\end{tabular}




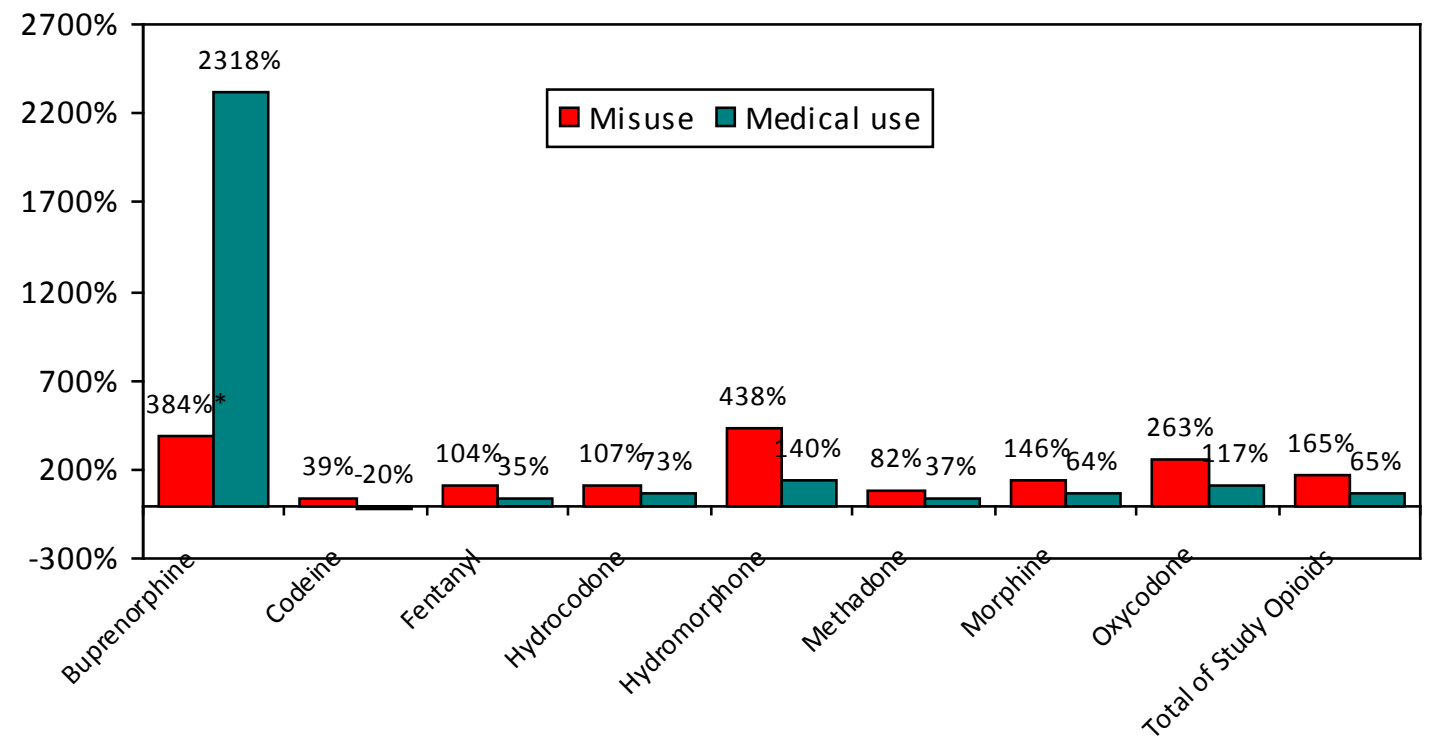

Fig. 1. Percentage of change of medical use and misuse of opioids from 2004 to 2011.

Table 2. Medical use and misuse of opioids based on data from Automation of Reports and Consolidated Orders System (ARCOS) and Drug Abuse Warning Network (DAWN).

\begin{tabular}{|c|c|c|c|c|c|c|c|c|c|c|}
\hline \multirow{2}{*}{ Drug Name } & \multicolumn{8}{|c|}{ Number of DAWN Visits: } & \multirow{2}{*}{$\begin{array}{c}\text { Percent } \\
\text { change from } \\
2004 \text { to } 2011 \\
\text { (Misuse) }\end{array}$} & \multirow{2}{*}{$\begin{array}{c}\text { Percent change } \\
\text { from } \\
\text { 2004 to 2011 } \\
\text { (Medical Use) }\end{array}$} \\
\hline & 2004 & 2005 & 2006 & 2007 & 2008 & 2009 & 2010 & 2011 & & \\
\hline Buprenorphine & NA & NA & 4,440 & 7,136 & 12,544 & 14,266 & 15,778 & 21,483 & $384 \% *$ & $2,318 \%$ * \\
\hline Codeine & 7,176 & 6,181 & 6,929 & 5,668 & 8,235 & 7,962 & 7,928 & 9,927 & $39 \%$ & $(-20 \%)$ \\
\hline Fentanyl & 9,823 & 11,211 & 16,012 & 15,947 & 20,179 & 20,945 & 21,196 & 20,034 & $104 \%$ & $35 \%$ \\
\hline Hydrocodone & 39,846 & 47,194 & 57,550 & 65,734 & 89,052 & 86,258 & 95,972 & 82,480 & $107 \%$ & $73 \%$ \\
\hline Hydromorphone & 3,385 & 4,717 & 6,780 & 9,497 & 12,142 & 14,337 & 17,666 & 18,224 & $438 \%$ & $140 \%$ \\
\hline Methadone & 36,806 & 42,684 & 45,130 & 53,950 & 63,629 & 63,031 & 65,945 & 66,870 & $82 \%$ & $37 \%$ \\
\hline Morphine & 14,090 & 15,762 & 20,416 & 29,591 & 28,818 & 31,731 & 29,605 & 34,593 & $146 \%$ & $64 \%$ \\
\hline Oxycodone & 41,701 & 52,943 & 64,891 & 76,684 & 105,526 & 148,974 & 146,355 & 151,218 & $263 \%$ & $117 \%$ \\
\hline $\begin{array}{l}\text { Total of Study } \\
\text { Opioids }\end{array}$ & 152,827 & 180,692 & 222,148 & 264,207 & 340,125 & 387,504 & 400,445 & 404,829 & $165 \%$ & $65 \%$ \\
\hline
\end{tabular}

$\mathrm{NA}=$ not available

${ }^{*}$ Percent change between $2006 \& 2011$

(690\% increase in medical use and a 1,372\% increase in misuse). This increase was less dramatic between 2004 and 2011 when there was an increase in use and misuse of $100 \%$ and $245 \%$, respectively (Table 3 ).

Prescription opioids as a percentage of overall drug mentions in DAWN also increased dramatically from $4 \%$ in 1996 to $20 \%$ in 2011. During the same time period, illicit drugs as a percentage of overall drug mentions decreased from 33\% in 1996 to $27 \%$ in 2011.

Data about patients seeking rehabilitation for prescription opioids was not available prior to 2007. Patients seeking detox for prescription opioids has increased by $187 \%$ from 2007 to 2011 (Table 4). During this period, patients seeking detox for marijuana and 
Table 3. Comparison of opioid use and misuse. *

\begin{tabular}{|l|r|r|r|r|r|r||}
\hline \multirow{2}{*}{} & \multicolumn{3}{|c|}{ Year } & \multicolumn{3}{c||}{ Percent change comparison } \\
\cline { 2 - 7 } & \multicolumn{1}{|c|}{$\mathbf{1 9 9 6}$} & \multicolumn{1}{c|}{$\mathbf{2 0 0 4}$} & $\mathbf{2 0 1 1}$ & $\mathbf{1 9 9 6}$ and $\mathbf{2 0 1 1}$ & $\mathbf{1 9 9 6}$ and 2004 & $\mathbf{2 0 0 4}$ and 2011 \\
\hline Opioid Use & $5,660,486$ & $44,688,402$ & $89,293,836$ & $1,448 \%$ & $690 \%$ & $100 \%$ \\
\hline Opioid Misuse (DAWN Visits) & 4,688 & 68,999 & 224,069 & $4,680 \%$ & $1,372 \%$ & $245 \%$ \\
\hline
\end{tabular}

${ }^{*}$ Statistics for fentanyl, hydromorphone, meperidine, morphine, and oxycodone only

Table 4. Number of patients seeking rehabilitation for substance abuse.

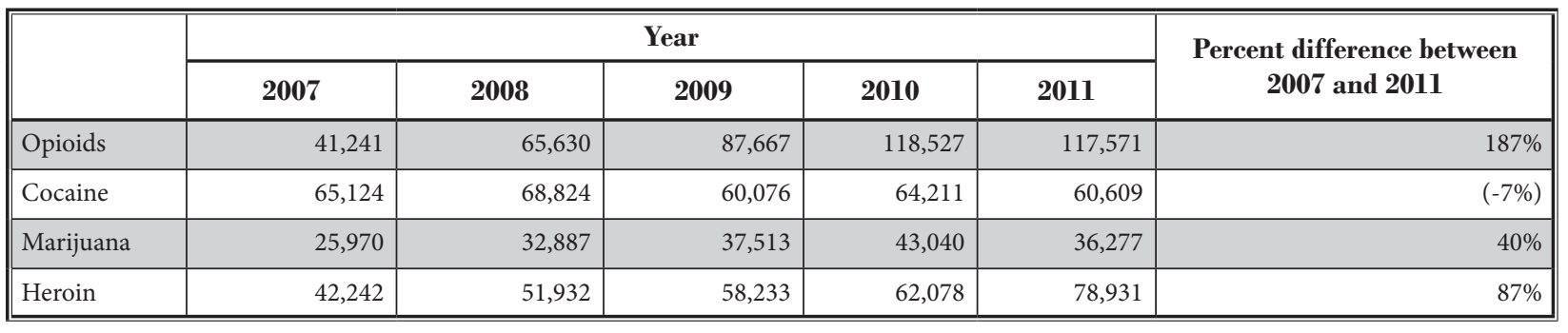

heroin also increased by $40 \%$ and $87 \%$, respectively. There was a $7 \%$ decrease in patients looking for detox for cocaine (Table 4).

\section{Discussion}

The examination of trends among opioids from 2004 to 2011 showed increased opioid use for individual opioids except for codeine and overall increased misuse of all opioids including codeine. The proportions of increase of medical use ranged from 2,318\% for buprenorphine to a decrease of $20 \%$ for codeine, with a $140 \%$ increase for hydromorphone, $117 \%$ increase for oxycodone, $73 \%$ increase for hydrocodone, $64 \%$ increase for morphine, and 35\% increase for fentanyl, and an overall increase of study opioids of $65 \%$. During the same period, the overall misuse of all opioids increased to $165 \%$ versus $65 \%$ of medical use, with hydromorphone showing a $438 \%$ increase, buprenorphine a $384 \%$ increase, oxycodone a $263 \%$ increase, morphine a $146 \%$ increase, hydrocodone a $107 \%$ increase, fentanyl $104 \%$, methadone $82 \%$, and codeine $39 \%$, despite the reduction in medical use of codeine.

This assessment shows an alarming increase in the medical use of buprenorphine, for which data is only available from 2006. The usage increase was $2,318 \%$ and the misuse increase was 384\% from 2006 to 2011. Even more alarming was the increase of hydromorphone by $140 \%$ from 2004 to 2011 with its misuse escalating to $438 \%$. Methadone also showed a $37 \%$ increase in usage with an increase of $82 \%$ in misuse. Fentanyl showed an increase of $35 \%$ with an increase of misuse of $104 \%$; hydrocodone showed an increase in medical use of $73 \%$ and misuse of $107 \%$; morphine $64 \%$ and $146 \%$; and oxycodone showed a $117 \%$ increase of medical use and $263 \%$ increase in misuse. Codeine showed a decrease of $20 \%$ in medical use, but an increase of $38 \%$ misuse.

The first comparison made between the DAWN and ARCOS data during the years from 1990 to 1996 showed an increase in the use of opioids without an increase in misuse (1). When the same data was compared again from the years 1997 to 2002 (2), during a phase of generous opioid use for chronic pain, there was a significant increase in the misuse of opioids in line with our findings. Furthermore, increased opioid use has multiplied the number of patients seeking rehabilitation from prescription opioids.

From 2004 to 2011 the increase in use and misuse, although significant, is much less dramatic than the period between 1996 and 2004 (Table 3). This comparative reduction in opioid use from 2004 is probably a reflection of cautious prescribing due to a growing awareness of the dangers of prescription opioids from media reports and legislation from states passing new laws regarding opioid prescribing. Although use and misuse was not as dramatic from 2004 to 2011 when compared to 1996 and 2004, the percentage of prescription opioid misuse relative to overall drug abuse has been steadily increasing since 1996, while the percentage of illicit drugs is gradually decreasing. Ideally, increased opioid use should be associated with decreased misuse and a decrease in pain prevalence. However, there is no evidence that the escalation of opioid use over the last 
decade and a half has resulted in the reduction of the prevalence of disability related to chronic pain $(3,4,32$ 35), with ample evidence instead suggesting that the escalation of opioid use is directly causing harm to the individual, the family, and to society $(3-6,14-17,24-28)$. Increased prescribing is leading to increased misuse in spite of Risk Evaluation and Management Strategies (REMS) (18) and Black Box Warnings from the Food and Drug Administration (FDA) (36). Thus, the prevalence of prescription opioid misuse continues to be on the rise despite efforts by governmental agencies like the FDA, DEA, Substance Abuse and Mental Health Services Administration (SAMHSA), National Institute on Drug Abuse (NIDA), and Centers for Disease Control and Prevention (CDC). In spite of recommendations from various authorities, multiple sources (3-5,15$17,20,21,23,26,35-47)$, and Senate investigations (48-50) that opioids for chronic pain should be used with caution and restraint, prescription opioid misuse continues to be on the rise. Since the medical community has not addressed this issue effectively, government has encroached to regulate opioid prescriptions. Many states passed laws to regulate prescribing opioids (51). The FDA recently announced that it does not recommend using long-acting opioids for moderate pain and that they should be reserved for only severe pain (7).

Among various measures, education is the most critical component in curtailing excessive prescription opioid use and preventing misuse and abuse, specifically for therapeutic opioids which have been issued for chronic pain $(4,5,14,15,17,18,20,24-26,52-66)$. However, this education must focus not only on physicians, but on patients and the industry in general. Patients must be educated in reference to indications and medical necessity, side effects, complications, and fatalities associated with opioid therapy, and physicians must also learn how to appropriately assess the patient, what constitutes medical necessity, and the potential for a diversion that may lead to serious or even lethal public health problems. Education, and an understanding of the physiology and pharmacology of chronic pain and the multiple modalities available for managing it, as well as comorbid factors, will assist physicians in establishing indications and medical necessity for chronic opioid therapy and in educating patients about these aspects. While the appropriate guidance from multiple sources must be developed and disseminated, it has been shown that regulations and guidelines do not sufficiently influence the clinical practice of opioid prescribing in chronic pain manage- ment (1-10,14,17,18,20,24-26,36,52-66). In fact, increased opioid prescribing coincided significantly with the liberalization of laws governing their prescription patterns and treatment of chronic non-cancer pain by state medical boards in the late 1990s (1-10,24). Many boards of medical licensures, continuing under misguided perceptions, may, in fact, be promoting rather than curtailing opioid use and abuse $(10,24)$. Furthermore, intractable pain acts in multiple states have educated patients in relation to their rights regarding pain, but have also fueled a growth in prescriptions.

In an evaluation of psychotherapeutic drug use in patients presenting to an interventional pain management setting, Manchikanti et al (67) showed that $94 \%$ of patients were on long-term opioids in the United States. Even though illicit drug use was also common, it had declined significantly since a previous publication. A large proportion of patients ( $49 \%$ ) had been on opioids of high doses of more than $40 \mathrm{mg}$ equivalence of morphine on a long-term basis, initiated and maintained by primary care physicians; $35 \%$ were on benzodiazepines and $9.2 \%$ on carisoprodol prior to presenting to interventional pain management. Almost all of the patients in this study that were prescribed opioids were deemed to have met medical necessity criteria by their prescribing physicians based on existing state laws at the time $(10,24,68,69)$. A closer look at various aspects of treatment shows that there was a lack of education in reference to comorbidities, conservative management, necessary assessment of indications, medical necessity, non-opioid interventions, adverse effects of opioid therapy, and monitoring for abuse. In fact, all physicians followed state board regulations in prescribing. Thus, the Federation and all licensure boards must be educated to use only that guidance which is appropriate $(24,68,69)$. Education has the potential to alter practice patterns that embrace shared decision-making. An acute understanding of the consequences is crucial to this paradigm shift - one that follows guidelines regarding the initial assessment, with comorbid issues and dose limitations and continuous monitoring $(4,5,54)$ involving various screening instruments $(4,5,68-72)$.

However, monitoring through prescription drug monitoring programs is easier and potentially more effective $(4,5,70-78)$. Urine drug testing and pill counts may become time consuming and cumbersome in busy practices $(4,5,72,79)$. Consequently, following an algorithmic approach, which includes appropriate urine drug testing, may reduce prescription drug overuse and abuse $(4,5,72,79)$. At present, there is no universally 
acceptable screening test proven to be accurate and effective (4,70-72). The effectiveness of interagency guidelines (39) was assessed and demonstrated by Franklin et al (80) illustrating bending prescription opioid dosing and reducing mortality. This assessment showed a substantial decline in the morphine equivalent dose per day of long-acting Schedule II opioids of $27 \%$ and the proportion of workers on doses equal to or greater than $120 \mathrm{mg}$ per day of morphine equivalent dosage by $35 \%$, as compared prior to 2007 . It also showed a $50 \%$ decrease from 2009 to 2010 in the number of deaths. Thus, it is of prime importance that patients be stratified into high and low risk categories after determination of medical necessity. In high risk patients, opioid use should be nonexistent or cautious with low doses and frequent monitoring. There is now ample evidence that the higher the dose, the higher the incidence of misuse $(14,24,25,75,81-84)$.

Among prescription opioid deaths, $80 \%$ occurred in patients receiving more than $100 \mathrm{mg}$ MED and $20 \%$ in those receiving less than $100 \mathrm{mg}$ morphine equivalent dose $(14,25)$. Generally patients not responding to low or moderate doses do not benefit from higher doses. Dose limitation is an important tool in the prevention of prescription opioid misuse. There is rarely a role for the justification for high dose opioid therapy, but it should be exercised carefully in well selected patients.

One study (85) of note showed that only $3 \%$ of physicians are responsible for $62 \%$ of all opioids prescribed. Recently, pharmacies have taken an active role in screening overprescribing physicians with prescription patterns that indicate abuse (76).

Limitations of this assessment include the lack of data from 2003, lack of data available on meperidine, and that the aggregate data systems used in the study did not identify specific formulations or commercial products. However, based on the present setting, we believe that this analysis provides appropriate data synthesis and at least provides a direction and confirms the correlation of increasing opioid use to misuse and resultant fatalities.

In addition, concerns about ARCOS and DAWN data have been expressed (2). ARCOS overestimates doses, as it includes veterinary doses, doses utilized for anesthesia, doses used to replace stolen medication, and doses sent to retail outlets but not dispensed. We agree that this may be an issue if checked for one particular year, but these concerns are less valid if the data is used to monitor trends. Concerns about DAWN data similarly are less valid if the data is used to monitor trends.

\section{Conclusion}

Increased opioid prescribing continues to result in the escalation of prescription opioid misuse. The goal of the medical community should be to decrease prescription opioid misuse. This may be achieved through the proper screening and selection of the patient for opioid therapy followed by appropriate monitoring (urine drug screens, prescription monitoring programs, and pill counts) and dose limitations.

\section{Acknowledgments}

The authors wish to thank Alvaro F. Gómez, MA, and Laurie Swick, BS, for manuscript review, and Tonie M. Hatton and Diane E. Neihoff, transcriptionists, for their assistance in preparation of this manuscript. We would like to thank the editorial board of Pain Physician for review and criticism in improving the manuscript.

Author Contributions: Drs. Manchikanti, Atluri, and Sudarshan developed the concept and devised the study. Drs. Atluri and Sudarshan acquired and synthesized the data from ARCOS and DAWN. All authors participated in preparation of the initial manuscript, multiple revisions for intellectual content, and final approval of the manuscript.

Disclosures: All the tasks of preparation of the manuscript were conducted with internal resources of the practices of the authors without external funding either from industry or from elsewhere.

\section{References}

1. Joranson DE, Ryan KM, Gilson AM, Dahl JL. Trends in medical use and abuse of opioid analgesics. JAMA 2000; 283:1710-1714.

2. Gilson $A M$, Ryan KM, Joranson DE, Dahl JL. A reassessment of trends in the medical use and abuse of opioid analgesics and implications for diversion control: 1997-2002.J Pain Symptom Manage
2004; 28:176-188.

3. Manchikanti L, Abdi S, Atluri S, Balog CC, Benyamin RM, Boswell MV, Brown KR, Bruel BM, Bryce DA, Burks PA, Burton AW, Calodney AK, Caraway DL, Cash KA, Christo PJ, Damron KS, Datta S, Deer TR, Diwan S, Eriator I, Falco FJE, Fellows B, Geffert S, Gharibo CG, Glaser SE, Grider JS, Hameed H, Hameed
M, Hansen H, Harned ME, Hayek SM, Helm II S, Hirsch JA, Janata JW, Kaye AD, Kaye AM, Kloth DS, Koyyalagunta D, Lee M, Malla Y, Manchikanti KN, McManus CD, Pampati V, Parr AT, Pasupuleti R, Patel VB, Sehgal N, Silverman SM, Singh V, Smith HS, Snook LT, Solanki DR, Tracy DH, Vallejo R, Wargo BW. American Society of Interventional Pain Physicians 
(ASIPP) guidelines for responsible opioid prescribing in chronic non-cancer pain: Part I - Evidence assessment. Pain Physician 2012; 15:S1-S66.

4. Manchikanti L, Abdi S, Atluri S, Balog CC, Benyamin RM, Boswell MV, Brown KR, Bruel BM, Bryce DA, Burks PA, Burton AW, Calodney AK, Caraway DL, Cash KA, Christo PJ, Damron KS, Datta S, Deer TR, Diwan S, Eriator I, Falco FJE, Fellows B, Geffert S, Gharibo CG, Glaser SE, Grider JS, Hameed H, Hameed M, Hansen $\mathrm{H}$, Harned ME, Hayek SM, Helm II S, Hirsch JA, Janata JW, Kaye AD, Kaye AM, Kloth DS, Koyyalagunta D, Lee M, Malla Y, Manchikanti KN, McManus CD, Pampati V, Parr AT, Pasupuleti $R$, Patel VB, Sehgal N, Silverman SM, Singh V, Smith HS, Snook LT, Solanki DR, Tracy DH, Vallejo R, Wargo BW. American Society of Interventional Pain Physicians (ASIPP) guidelines for responsible opioid prescribing in chronic non-cancer pain: Part 2 - Guidance. Pain Physician 2012; 15:S67-S116.

5. Manchikanti L, Boswell MV, Hirsch JA. Lessons learned in the abuse of painrelief medication: A focus on healthcare costs. Expert Rev Neurother 2013; 13:527-543.

6. Inocencio TJ, Carroll NV, Read EJ, Holdford DA. The economic burden of opioid-related poisoning in the United States. Pain Med 2013 [Epub ahead of print].

7. U.S. Food and Drug Administration News Release: FDA announces safety labeling changes and postmarket study requirements for extended-release and long-acting opioid analgesics. September 10, 2013.

www.fda.gov/NewsEvents/Newsroom/ PressAnnouncements/ucm367726.htm.

8. Manchikanti L, Helm II S, Fellows B, Janata JW, Pampati V, Grider JS, Boswell MV. Opioid epidemic in the United States. Pain Physician 2012; 15:ES9-ES38.

9. Eriksen J, Sjogren P, Bruera E, Ekholm $\mathrm{O}$, Rasmussen NK. Critical issues on opioids in chronic noncancer pain: an epidemiological study. Pain 2006; 125:172-179.

10. Federation of State Medical Boards of the US. Model guidelines for the use of controlled substances for the treatment of pain: A policy document of the Federation of State Medical Boards of the United States, Inc., Dallas, TX, 1998.

11. Chou R, Fanciullo GJ, Fine PG, Adler JA, Ballantyne JC, Davies P, Dono- van MI, Fishbain DA, Foley KM, Fudin J, Gilson AM, Kelter A, Mauskop A, O'Connor PG, Passik SD, Pasternak GW, Portenoy RK, Rich BA, Roberts RG, Todd $\mathrm{KH}$, Miaskowski C; American Pain Society-American Academy of Pain Medicine Opioids Guidelines Panel. Clinical guidelines for the use of chronic opioid therapy in chronic noncancer pain.J Pain 2009;10:113-130.

12. Phillips DM. JCAHO pain management standards are unveiled. Joint Commission on Accreditation of Healthcare Organizations. JAMA 2000; 284:428-429.

13. McDonald DC, Carlson KE. Estimating the prevalence of opioid diversion by "doctor shoppers" in the United States. PLOS One 2013; 8:e69241.

14. Centers for Disease Control and Prevention. CDC grand rounds: Prescription drug overdoses - a U.S. epidemic. MMWR Morb Mortal Wkly Rep 2012; 61:10-13.

15. Kuehn BM. Prescription drug abuse rises globally. JAMA 2007; 297:1306.

16. Jones CM, Mack KA, Paulozzi LJ. Pharmaceutical overdose deaths, United States, 2010. JAMA 2013; 309:657-659.

17. US Government Accountability Office: Report to Congressional Requesters. Prescription Pain Reliever Abuse, December 2011.

www.gao.gov/assets/590/587301.pdf.

18. Nelson LS, Perrone J. Curbing the opioid epidemic in the United States: The risk evaluation and mitigation strategy (REMS). JAMA 2012; 308:457-458.

19. Katz MH. Opioid prescriptions for chronic nonmalignant pain: Driving on a dangerous road. JAMA Intern Med 2013; 173:178.

20. Volkow ND, McLellan TA. Curtailing diversion and abuse of opioid analgesics without jeopardizing pain treatment. JAMA 2011; 305:1346-1347.

21. Bohnert AS, Valenstein M, Bair MJ, Ganoczy D, McCarthy JF, Ilgen MA, Blow FC. Association between opioid prescribing patterns and opioid overdose-related deaths. JAMA 2011; 3051315-1321.

22. Kuehn BM. Alarming nonfatal overdose rates found for opioids, sedatives, and tranquilizers. JAMA 2010; 303:2020-2021.

23. Wisniewski AM, Purdy $\mathrm{CH}$, Blondell RD. The epidemiologic association between opioid prescribing, non-medical use, and emergency department visits. J Addict Dis 2008; 27:1-11.

24. Federation of State Medical Boards.
Model guidelines for the use of opioid analgesics in the treatment of chronic pain. July 2013. www.fsmb.org/pdf/ pain_policy_julyzor3.pdf .

25. Centers for Disease Control and Prevention (CDC). Vital signs: Overdoses of prescription opioid pain relieversUnited States, 1999-2008. MMWR Morb Mortal Wky Rep 2011; 60:1487-1492.

26. Physicians for Responsible Opioid Prescribing (PROP).

/www.supportprop.org/

27. Report of the International Narcotics Control Board for 2011. United Nations, New York, NY, USA (2011). www. unodc.org/documents/southasia/reports/2011_INCB_ANNUAL_REPORT_ english_PDF.pdf.

28. United Nations Office on Drugs and Crime. Ensuring availability of controlled medications for the relief of pain and preventing diversion and abuse: Striking the right balance to achieve the optimal public health outcome. Discussion paper based on a scientific workshop. UNODC, Vienna, Austria, January 18-19, 2011. www.unodc.org/docs/treatment/ Pain/Ensuring_availability_of_controlled_medications_FINAL_15_March_ CND_version.pdf.

29. Drug Abuse Warning Network. New DAWN: Why it cannot be compared with old DAWN. The New Dawn Report. September 2005. www.samhsa.gov/data/ DAWN/DAWN\%20-\%2onew\%20vs\%20 old.pdf.

30. U.S. Department of Justice. Office of Diversion Control. Automation of Reports and Consolidated Orders System (ARCOS). www.deadiversion.usdoj.gov/ arcos/.

31. Substance Abuse and Mental Health Services Administration, Drug Abuse Warning Network. www.samhsa.gov/ data/dawn.aspx.

32. Freburger JK, Holmes GM, Agans RP, Jackman AM, Darter JD, Wallace AS, Castel LD, Kalsbeek WD, Carey TS. The rising prevalence of chronic low back pain. Arch Intern Med 2009; 169:251-258.

33. Hoy DG, Bain C, Williams G, March L, Brooks P, Blyth F, Woolf A, Vos T, Buchbinder R. A systematic review of the global prevalence of low back pain. Arthritis Rheum 2012; 64:2028-2037.

34. Hoy D, Brooks P, Blyth F, Buchbinder $R$. The epidemiology of low back pain. Best Pract Res Clin Rheumatol 2010; 24:769-781.

35. U.S. Social Security Administration. An- 
nual statistical report on the Social Security Disability Insurance Program, 2011. Release July 2012. www.ssa.gov/ policy/docs/statcomps/di_asr/2011/di_ asri1.pdf.

36. O'Connor NR. FDA boxed warnings: How to prescribe drugs safely. Am Fam Physician 2010; 81:298-303.

37. British Pain Society. Opioids for persistent pain: Good practice. A consensus statement prepared on behalf of the British Pain Society, the Royal College of Anaesthetists, the Royal College of General Practitioners and the Faculty of Addictions of the Royal College of Psychiatrists. London, UK, The British Pain Society, January 2010. www.britishpainsociety.org/book_opioid_main.pdf.

38. National Opioids Use Guideline Group (NOUGG). Canadian guidelines for safe and effective use of opioids for chronic non-cancer pain, Recommendations for Practice, Version 5.6. April 30, 2010. http://nationalpaincentre.mcmaster.ca/ documents/opioid_guideline_part_b_ v5_6.pdf.

39. Agency Medical Directors Group. Interagency guidelines on opioid dosing for chronic non-cancer pain: An educational aid to improve care and safety with opioid therapy. 2010 Update. www. agencymeddirectors.wa.gov/Files/OpioidGdline.pdf.

40. Stein C, Reinecke H, Sorgatz H. Opioid use in chronic noncancer pain: Guidelines revisited. Curr Opin Anaesthesiol 2010; 23:598-601.

41. Reinecke H, Sorgatz H; German Society for the Study of Pain (DGSS). S3 guideline LONTS. Long-term administration of opioids for non-tumor pain. Schmerz 2009; 23:440-447.

42. Hughes MA, Biggs JJ, Thiese MS, Graziano K, Robbins RB, Effiong AC. Recommended opioid prescribing practices for use in chronic non-malignant pain: A systematic review of treatment guidelines. J Manage Care Med 2011; 14:52-58.

43. Volkow ND, McLellan TA, Cotto JH, Karithanom M, Weiss SR. Characteristics of opioid prescriptions in 2009. JAMA 2011; 305:1299-1301.

44. McLellan AT. Treatment given high priority in new White House drug control policy. Interview by Bridget Kuehn. JAMA 2010; 303:821-822.

45. McLellan AT, Turner B. Prescription opioids, overdose deaths, and physician responsibility. JAMA 2008; 300:2672-2673.

46. Kuehn BM. Efforts aim to curb opi- oid deaths, injuries. JAMA 2009; 301:1213-1215.

47. Kuehn BM. Opioid prescriptions soar: Increase in legitimate use as well as abuse. JAMA 2007; 297:249-251.

48. Fauber J. MedPage Today/Milwaukee Journal Sentinel series triggers senate investigation. Medpage Today, May 9, 2012. www.medpagetoday.com/PainManagement/ PainManagement $/ 32582$.

49. Meier B. Senate inquiry into painkiller makers' ties. New York Times, May 8 2012. www.nytimes.com/2012/05/o9/ health/senate-panel-to-examinenarcotic-drug-makers-financial-ties. html?_r=o.

50. Ornstein C, Weber T. American Pain Foundation shuts down as senators launch investigation of prescription narcotics. ProPublic, May 8, 2012. www. propublica.org/article/senate-panel-investigates-drug-company-ties-to-paingroups.

51. Centers for Disease Control and Prevention. Prescription Drug Overdose: State Law. www.cdc.gov/HomeandRecreationalSafety/poisoning/laws/index. html.

52. Gudin JA. The changing landscape of opioid prescribing: Long-acting and extended-release opioid class-wide Risk Evaluation and Mitigation Strategy. Ther Clin Risk Manag 2012; 8:209-217.

53. Peppin JF, Coleman JJ, Kirsh KL. Issues and critiques of the forthcoming risk evaluation and mitigation strategy (REMS) for opioids in pain management. Issues Law Med 2011; 27:91-119.

54. Manchikanti L, Hirsch JA. The pains of chronic opioid usage [Spotlight]. AHRQ WebM\&M [serial online]. September 2013. http://webmm.ahrq.gov/case. aspx?caselD=305.

55. Mercadante S, Craig D, Giarratano A US Food and Drug Administration's Risk Evaluation and Mitigation Strategy for extended-release and long-acting opioids: Pros and cons, and a European perspective. Drugs 2012; 72:2327-2332.

56. Stanos S. Evolution of opioid risk management and review of the classwide REMS for extended-release/long-acting opioids. Phys Sportsmed 2012; 40:12-20.

57. Juurlink DN, Dhalla IA, Nelson LS. Improving opioid prescribing: the New York City recommendations. JAMA 2013; 309:879-880.

58. Alford DP. Chronic back pain with possible prescription opioid misuse. JAMA
2013; 309(9):919-925

59. Dowell D, Kunins HV, Farley TA. Opioid analgesics--risky drugs, not risky patients. JAMA 2013; 309:2219-2220.

6o. Kuehn BM. FDA tightens indications for using long-acting and extended-release opioids to treat chronic pain. JAMA 2013; 310:1547-1548.

61. Kuehn BM. FDA committee: More restrictions needed on hydrocodone combination products. JAMA 2013; 309:862.

62. Kopelow M. Continuing education in opioid prescribing. JAMA 2012; 308:2081-2082.

63. Alexander GC, Kruszewski SP, Webster DW. Rethinking opioid prescribing to protect patient safety and public health. JAMA 2012; 308:1865-1866.

64. Kuehn BM. Petition targets painkiller marketing in effort to curb overdose deaths. JAMA 2012; 308:1194-1196.

65. Kuehn BM. Methadone overdose deaths rise with increased prescribing for pain. JAMA 2012; 308:749-750.

66. Kuehn BM. Scientists, officials eye tools aimed at combating abuse of painkillers. JAMA 2012; 307:19-21.

67. Manchikanti L, Cash KA, Malla Y, Pampati $V$, Fellows B. A prospective evaluation of psychotherapeutic and illicit drug use in patients presenting with chronic pain at the time of initial evaluation. Pain Physician 2013; 16:E1-E13.

68. Kentucky Board of Medical Licensure (KBML). Guidelines for the Use of Controlled Substances in Pain Treatment. http://media.kentucky.com/smedia/2008/08/01/19/UseofCSsinPainTreatment.source.prod_affiliate.79.pdf.

69. Fishman SM, Federation of State Medical Boards of the United States. Responsible Opioid Prescribing: A Clinician's Guide. (2nd Edition, Revised and Expanded). Washington, DC: Waterford Life Science; 2012.

70. Solanki DR, Koyyalagunta D, Shah RV, Silverman SM, Manchikanti L. Monitoring opioid adherence in chronic pain patients: Assessment of risk of substance misuse. Pain Physician 2011; 14:E119-E131.

71. Sehgal N, Manchikanti L, Smith HS. Prescription opioid abuse in chronic pain: A review of opioid abuse predictors and strategies to curb opioid abuse. Pain Physician 2012; 15:ES67-ES92.

72. Atluri S, Akbik H, Sudarshan G. Prevention of opioid abuse in chronic noncancer pain: an algorithmic, evidence based approach. Pain Physician 2012; 
15:ES177-ES189.

73. Paulozzi LJ, Kilbourne EM, Desai HA. Prescription drug monitoring programs and death rates from drug overdose. Pain Med 2011; 12:747-754.

74. Betses M, Brennan T. Abusive prescribing of controlled substances - a pharmacy view. N Engl J Med 2013; 369:989-991.

75. Heins JR, Lambrechts E. Prescription drug monitoring programs. S D Med 2013; 66:191, 193.

76. Garcia AM. State laws regulating prescribing of controlled substances: Balancing the public health problems of chronic pain and prescription painkiller abuse and overdose. J Law Med Ethics 2013; 41:42-45.

77. Gugelmann H, Perrone J, Nelson L. Windmills and pill mills: Can PDMPs tilt the prescription drug epidemic? J Med Toxicol 2012; 8:378-386.
78. Chakravarthy B, Shah S, Lotfipour S. Prescription drug monitoring programs and other interventions to combat prescription opioid abuse. West J Emerg Med 2012; 13:422-425.

79. Christo PJ, Manchikanti L, Ruan X, Bottros $M$, Hansen $H$, Solanki D, Jordan AE, Colson J. Urine drug testing in chronic pain. Pain Physician 2011; 14:123-143.

8o. Franklin GM, Mai J, Turner J, Sullivan M, Wickizer T, Fulton-Kehoe D. Bending the prescription opioid dosing and mortality curves: Impact of the Washington State opioid dosing guideline. Am J Ind Med 2012; 55:325-331.

81. Bohnert AS, Valenstein M, Bair MJ, Ganoczy D, McCarthy JF, Ilgen MA, Blow FC. Association between opioid prescribing patterns and opioid overdoserelated deaths. JAMA 2011; 305:1315-1321.

82. Dunn KM, Saunders KW, Rutter CM, Banta-Green CJ, Merrill JO, Sullivan
MD, Weisner CM, Silverberg MJ, Campbell $\mathrm{Cl}$, Psaty BM, Von Korff M. Overdose and prescribed opioids: Associations among chronic non-cancer pain patients. Ann Intern Med 2010; 152:85-92.

83. Braden JB, Russo J, Fan MY, Edlund MJ, Martin BC, DeVries A, Sullivan MD. Emergency department visits among recipients of chronic opioid therapy. Arch Intern Med 2010; 170:1425-1432.

84. Gomes T, Juurlink DN, Dhalla IA, MailisGagnon A, Paterson JM, Mamdani MM. Trends in opioid use and dosing among socio-economically disadvantaged patients. Open Med 2011; 5:e13-e22.

85. Swedlow A, Ireland J, Johnson G. Prescribing patterns of Schedule II opioids in California Workers' Compensation. Oakland, CA: California Workers' Compensation Institute, March 2011. www. cwci.org/document.php?file=1438.pdf. 